Original Article

\title{
SYNTHESIS AND CHARACTERIZATION OF A NOVEL MUCOADHESIVE DERIVATIVE OF PSYLLIUM SEED POLYSACCHARIDE
}

\author{
MONICA R. P. RAO*1, SNEHAL R. GAIKWAD ${ }^{\text {, PRACHI M. SHEVATE }}{ }^{1}$ \\ 1Department of Pharmaceutics, AISSMS College of Pharmacy, Near RTO, Kennedy Road, Pune 411001, Maharashtra, India \\ Email: monicarp_6@hotmail.com
}

Received: 22 Jul 2016 Revised and Accepted: 09 May 2017

\section{ABSTRACT}

Objective: In the present study, thiol-functionalization of psyllium seed polysaccharide (PSY) was cross-linked with thioglycolic acid by esterification in an attempt to reveal the mucoadhesive properties of thiolated psyllium seed polysaccharide (TPSY).

Methods: The crosslinking was carried out by the microwave-assisted method. A simplex centroid design was employed to systematically study the mucoadhesive strength, mucoadhesive retention time and drug release profile. Comparative evaluation of carbopol-based ciprofloxacin hydrochloride $(\mathrm{HCl})$ tablets containing PSY and TPSY was carried out. Acute oral toxicity studies and repeated oral toxicity for TPSY were also conducted.

Results: Thiol-functionalization was confirmed by-SH stretch in Fourier Transform infra-red spectra at $2353 \mathrm{~cm}^{-1}$. Thiolation was observed in thiolated PSY (TPSY) by a change in the surface morphology of psyllium from fibrous to granular and resulted in $82 \%$ swelling in deionized water. TPSY was found to contain $102.35 \mathrm{mmol}$ of thiol groups/g as determined by the Ellman's method. The percent increase in mucoadhesive strength of TPSY was found to be $50.31 \%$ as compared to PSY and $128.30 \%$ as compared to carbopol. The percent increase in mucoadhesive retention time of TPSY was found to be $110 \%$ as compared to PSY and $50 \%$ as compared to carbopol.

Conclusion: Mucoadhesion strength and mucoadhesive retention time were greater of tablets containing a higher amount of TPSY. Further, the acute oral toxicity studies and repeated oral toxicity for TPSY proved it as non-toxic and hence safe for human use.

Keywords: Psyllium seed polysaccharide, Crosslinking, Microwave assisted, Thiolated psyllium seed polysaccharide

(C) 2017 The Authors. Published by Innovare Academic Sciences Pvt Ltd. This is an open access article under the CC BY license (http://creativecommons.org/licenses/by/4.0/) DOI: http://dx.doi.org/10.22159/ijpps.2017v9i6.14221

\section{INTRODUCTION}

Natural polysaccharides have widespread applications as biopolymers as they are economical, easily available in a variety of structures. They can be modified easily by the chemical and biochemical process. Along with other properties like stability, safety and biodegradability, they suggest use in targeted drug delivery systems. Also, they find extensive applications in pharmaceutical and food industry because of their diversity in structure and properties [1, 2].

Psyllium, also known as ispaghula comprises of seed husks of Plantago ovata forsk (family Plantaginaceae). The laxative and prolonged action of Plantago husk have been attributed to the gel forming fraction of the husk. Psyllium mucilage obtained from psyllium husk is white fibrous hydrophilic material that forms a clear colourless mucilaginous gel by absorbing water. The polysaccharides extracted from the husk of Plantago ovata have been chemically characterised to contain a high proportion of hemicellulose which is the alkali soluble fraction of the husk. It consists of highly branched acidic arabinoxylan comprising of xylan backbone chain with xylose and arabinose forming the side chains [3].

Psyllium husk has been reported for the treatment of constipation, diarrhea, irritable bowel syndrome, inflammatory bowel disease ulcerative colitis, colon cancer, diabetes and hypercholesterolemia [4].

Phosphorylated PSY has been investigated as a release retardant and binder $[5,6]$. Acrylamide-crosslinked psyllium husk is reported as hydrogel for antibiotic drug delivery [7]. Psyllium husk radiated by crosslinked N-vinyl pyrrolidone has been proved as hydrogels for anticancer drug delivery [8].

Mucoadhesive dosage forms may be designed to enable prolonged retention at the site of application, providing a controlled rate of drug release for improved therapeutic outcome [9]. Mucoadhesion of natural polymers by thiolation has been used to improve the mucoadhesive and cohesive properties of the polymers.
Hydroxyethylcellulose (HEC) modified with thiourea was studied for mucoadhesive delivery systems [10]. Chitosan was cross-linked with 2 -iminothiolane and reported as having increased mucoadhesive properties [11]. Carboxymethyl dextran was modified by the covalent attachment of cysteine which improved the mucoadhesive properties [12].

In the present study, an attempt was made to improve the mucoadhesive properties of PSY by thiol-functionalization [13]. Thiolation was carried out using the microwave-assisted method to improve the efficiency of the synthetic process $[14,15]$. Thiol group estimation was done by Ellman's reagent assay. The thiolated conjugate (TPSY) was characterized by Fourier transform infrared spectroscopy (FTIR), differential scanning calorimetry (DSC), X-Ray diffractometry (XRD) and field emission scanning electron microscopy (FESEM). Mucoadhesive characteristics of psyllium were comparatively evaluated with thiolated-psyllium by conducting tensile tests employing texture analyser.

Acute oral toxicity and repeated oral toxicity studies for TPSY were also conducted. A simplex centroid design containing 7 experimental runs to evaluate the effect of polymers i.e. PSY, TPSY and carbopol was employed to determine their effect on three responses i.e. mucoadhesive strength, retention time and percent drug release and their interaction. Ciprofloxacin HCL (CIP) was selected as a model drug for preparing the tablets.

\section{MATERIALS AND METHODS}

\section{Materials}

Psyllium seeds were obtained from Manakarnika Aushadalay, Pune. Thioglycolic acid was a gift sample from Molychem, Mumbai. All the other chemicals, solvents and reagents used were of analytical grade and were procured locally. Dialysis membrane (HiMedia LA 401) was used for purification of crosslinked conjugate. Ciprofloxacin HCL (CIP) was supplied by Aarti Drugs Ltd. Mumbai. 


\section{Methods}

\section{Thiolation by microwave assissted method}

TPSY was synthesised by microwave assisted esterification of PSY with thioglycolic acid in the presence of hydrochloric acid. The reaction was carried out with 2 moles of thioglycolic acid for every mole of the hydroxyl group in PSY. Psyllium seed powder was soaked in water (1:50) overnight and the $\mathrm{pH}$ of the mixture was adjusted to 12 with sodium hydroxide $(2.5 \% \mathrm{w} / \mathrm{v})$ solution [16]. The mixture was transferred to a two-neck round bottom flask and placed on the turntable of a microwave oven (Microwave Catalyst system CATA 2R). An electronic thermometer with an alarm set at $70{ }^{\circ} \mathrm{C}$ was incorporated into the reaction vessel. This was to ensure that the reaction temperature did not cross $70{ }^{\circ} \mathrm{C}$. Microwave irradiation at $340 \mathrm{~W}$ was performed for 10 min followed by $425 \mathrm{~W}$ for $10 \mathrm{~min}$ [17]. The reaction mixture was cooled and precipitated by adding methanol followed by washing of precipitate with methanol to remove the unreacted thioglycolic acid. TPSY so obtained was frozen at $-80^{\circ} \mathrm{C}$ for $4 \mathrm{~h}$ followed by lyophilization in a laboratory model freeze drier (2.5 Freezone Labconco equipment limited) at $-90^{\circ} \mathrm{C}$ and 0.0010 mbar pressure for $24 \mathrm{~h}$.

\section{Purification by dialysis}

Dialysis membrane (HiMedia LA 401) with a cut-off molecular weight between 5000-10000 daltons was soaked overnight in distilled water. A section of required dimensions was cut and one end was tied and filled with the synthesized product. The other end was then tied securely to prevent any leakage and it was immersed in a beaker containing $50 \mathrm{ml}$ dialysing solvent i.e. methanol. The temperature was maintained at $25^{\circ} \mathrm{C}$ and the system stirred for $24 \mathrm{~h}$ with a magnetic stirrer. The sample was then removed and air dried for $3 \mathrm{~h}$. The dialyzed product was then subjected to further characterization [18].

\section{Determination of thiol substitution}

The degree of thiol group substitution was determined by Ellman's method. Aqueous dispersions $(0.5 \%, \mathrm{w} / \mathrm{v})$ of TPSY and PSY (as control) were prepared and diluted with phosphate buffer $(5 \mathrm{M}, \mathrm{pH}$ 8.0) to a concentration of $0.15 \% \mathrm{w} / \mathrm{v}$. An aliquot of $5 \mathrm{ml}$ of the polymer solution was allowed to react with $5 \mathrm{ml}$ of Ellman's reagent (5.5-dithio bis (2-nitrobenzoic acid) $(0.3 \% \mathrm{w} / \mathrm{v})$ for $2 \mathrm{~h}$ at room temperature, followed by measurement of absorbance at $450 \mathrm{~nm}$. The numbers of thiol group substituents per gram of TPSY were determined using a calibration curve prepared by reacting standard solutions of thioglycolic acid with Ellman's reagent [19].

\section{Characterization of psyllium seed polysaccharide (PSY) and} thiolated psyllium seed polysaccharide (TPSY)

The PSY and TPSY were characterized for physicochemical properties (solubility studies, swelling index and micromeritic properties), spectral analysis and thermal analysis. Acute oral toxicity studies and repeated oral toxicity were also conducted as per OECD Guidelines 423.

\section{Swelling Index}

Swelling index is indicative of the ability of polysaccharides to swell after absorbing fluids available at the site of absorption, which is mandatory for mucoadhesion. Swelling behavior of PSY and TPSY was studied at different $\mathrm{pH}$ such as $0.1 \mathrm{~N} \mathrm{HCl}(\mathrm{pH} 1.1)$, phosphate buffer $\mathrm{pH}$ 6.8, deionized water and $0.5 \mathrm{M} \mathrm{NaOH}$ (pH 13.7). For this, $1 \mathrm{~g}$ of PSY and TPSY were added separately in $25 \mathrm{ml}$ of the respective media in stoppered volumetric flasks at $37^{\circ} \mathrm{C}$ and kept overnight with intermittent shaking. The volume occupied by the PSY was measured using a measuring cylinder and swelling index was calculated from the initial and final volume of PSY and TPSY respectively [20].

\section{Solubility profile}

The solubility of PSY and TPSY was evaluated by modified gravimetric method at $37{ }^{\circ} \mathrm{C}$ in various solvents such as acetone, alcohol, ether, chloroform, dichloromethane, dimethyl amine, tri methylamine, diethyl ether, ethyl acetate, dimethyl sulfoxide, isopropyl alcohol, $0.5 \mathrm{~N}$ sodium hydroxide, $\mathrm{N}$-methyl-2-pyrrolidone, $\mathrm{N}, \mathrm{N}$-dimethyl formamide, conc. hydrochloric acid, formamide, ammonia, and conc. nitric acid by adding PSY and TPSY in increments of $0.1 \mathrm{~g}$ followed by sonication for $5 \mathrm{~min}$ [20].

\section{Micrometric properties}

The bulk density, tapped density, angle of repose, Hausner's ratio and Carr's index of PSY and TPSY was evaluated [21].

\section{Rheological properties}

The mucilages of PSY and TPSY were prepared in distilled water in strengths of $0.4,0.5,0.6,1$ and $2 \% \mathrm{w} / \mathrm{v}$. The mucilages were homogenized using tissue homogenizer to break any lumps and subjected to rheometry studies at different shear rates using Brookfield viscometer (Brookfield DV-E Viscometer) using Helipath spindle-E (6) at $25^{\circ} \mathrm{C}[20]$.

\section{Mucoadhesive strength}

The mucoadhesive strength of PSY and TPSY pellets were evaluated using Texture Analyzer (CEB Texture Analyzer, Brookfield Engineering Labs, Inc., Model Texture Pro CT V1.4 Build 17). The pellets $(100 \mathrm{mg})$ were prepared using a hydraulic press (Mini PressII MT, Make: Rimek). Fresh sheep gastric mucosa was procured from the local slaughter house and was washed with distilled water followed by $0.1 \mathrm{~N} \mathrm{HCl}$ and was carefully attached using a doublesided adhesive tape to the cylindrical probe (TA 3/100 Probe). The probe was brought manually downwards to pellet surface at a constant speed of $1 \mathrm{~mm} / \mathrm{sec}$ and predetermined compressive force of $0.5 \mathrm{~N}$ was applied with holding time $60 \mathrm{sec}$ with $1000 \mathrm{~g}$ load cell. The probe was then removed at a speed of $1 \mathrm{~mm} / \mathrm{s}$ and to a distance of $15 \mathrm{~mm}$, and maximum detachment force $(\mathrm{N})$ was determined with data rate 15 points/sec. A different mucosa sample was used for every new sample. The mucoadhesive strength, i.e. the maximum force required for separating the tablet from the mucosal surface was obtained [22].

\section{Mucoadhesion time}

The mucoadhesion time was evaluated by in vitro adhesion testing method known as the wash-off method using disintegration apparatus (Make: VEEGO VTD-2). Gastric mucosa was fixed on a glass slide using a double-sided adhesive tape and the pellet was wetted with a drop of $0.1 \mathrm{~N} \mathrm{HCl}$ and affixed to the mucosal tissue. The glass slide was then tied to the paddle with cotton thread of a USP disintegration apparatus containing $900 \mathrm{ml}$ of $0.1 \mathrm{~N} \mathrm{HCl}$ and rotated at $37 \pm 0.5{ }^{\circ} \mathrm{C}$. After $2 \mathrm{~min}$, a stirring rate of $25 \mathrm{rpm}$ was applied to simulate the gastric environment, and time taken for the tablet to detach from sheep gastric mucosal tissue was recorded as mucoadhesion time [23].

\section{Spectral analysis}

\section{Fourier transform infrared spectroscopy (FTIR)}

Infra-red spectrum of PSYand TPSY was recorded out on Jasco FTIR401, Japan at transmittance mode. Baseline correction was done using dried potassium bromide (KBr). $\mathrm{KBr}$ was initially dried and mixed in a ratio of 1:4 with PSYand TPSY. A small amount of triturated sample was kept into the sample holder and scanned from $4000 \mathrm{~cm}^{-1}$ to 400 $\mathrm{cm}^{-1}$ in FTIR spectrophotometer (FTIR 8400S, Shimadzu, Japan).

\section{Powder X-ray diffraction analysis (PXRD)}

PXRD patterns were recorded in the reflection mode on a Siemens D-500 X-ray diffractometer. Diffractograms were registered at Bragg angle (20) range of $5-40^{\circ}$ at a scan rate of $2.5^{\circ}$ per minute and step size of $0.02^{\circ}$. X-ray diffractogram on powdered samples were obtained using a Bruker AXS Advanced X-ray diffractometer under the following operating conditions: $40 \mathrm{kV}$ and $40 \mathrm{~mA}$ with $\mathrm{Cu}-\mathrm{K} \alpha$ radiation at $\mathrm{k}$ $1.54184 \AA$ and acceptance slot at $0.1 \mathrm{~mm}$. About $15-20 \mathrm{mg}$ of the sample was spread on a sample stage, and the relative intensity was recorded in the scattering range $(2 \AA)$ of $0-60^{\circ} \mathrm{C}$ in steps of $0.1^{\circ} \mathrm{C}$.

\section{Field emission scanning electron microscopy (FESEM)}

The surface morphology of PSY and TPSY were determined using FESEM (Instrument: FEI, model: Nova nano SEM 450). A field emission gun produces an electron beam with an extremely high 
current density, obtained by applying an intense electric field to a tungsten single crystal with a needle-shaped tip. This requires ultrahigh vacuum $(10-[10]$ Torr). The samples were sprinkled on a double adhesive tape stuck to an aluminium stub. The stubs were then coated with platinum to a thickness of about $10 \AA$ under an argon atmosphere using a gold sputter module in a high-vacuum. The stub containing the samples was placed in the FESEM chamber.

\section{Differential scanning calorimetry (DSC)}

The thermograms of PSY and TPSY were obtained by a DSC (DSC 821, Make: METTLER) at a heating rate of $10^{\circ} \mathrm{C} / \mathrm{min}$ from 30 to 300 ${ }^{\circ} \mathrm{C}$ in a nitrogen atmosphere $(30 \mathrm{ml} / \mathrm{min})$.

\section{Acute oral toxicity studies for TPSY}

Permission to perform the acute oral toxicity studies and repeat oral toxicity studies was obtained from Institutional Animal Ethics Committee (Approval No.: CPCSEA/IAEC/PT-05/01-2K16). An acute oral toxicity study was conducted according to OECD guidelines 423 . The study was performed in healthy male Wistar rats (200-300 g). Pilot study was carried out using six male Wistar rats in a group with the starting dose of $300 \mathrm{mg} / \mathrm{kg}$ body weight. Animals were monitored continuously immediately after dosing up to first $4 \mathrm{~h}$. The animals were observed for any sign of toxicity or mortality after $24 \mathrm{~h}$ and $14 \mathrm{~d}$. When $300 \mathrm{mg} / \mathrm{kg}$ dose was proved to be non-toxic, in the main study $2000 \mathrm{mg} / \mathrm{kg}$ dose was screened for checking toxicity using the above-mentioned procedure [24].

\section{Repeat dose (28 d) oral toxicity study}

Approval for animal studies was granted by CPCSEA with Approval number: CPCSEA/IAEC/PT-05/01-2k16. A 28 d repeat dose toxicity study was performed as per OECD Guidelines 407 (Adopted: 3 October 2008) for the optimised TPSY. Male Wistar rats, divided into 4 groups of five rats, were used for the study. The animals in group 1 served as vehicle controls and were administered normal saline daily by oral gavage. The animals in groups 2,3 and 4 were administered a daily dose of 70, 175 and $350 \mathrm{mg} / \mathrm{kg}$ body weight of TPSY as aqueous suspension by oral gavage for $28 \mathrm{~d}$ respectively.

All the animals were observed daily for clinical signs of toxicity and morbidity. Individual animal body weights were recorded at receipt (on day 1) and weekly thereafter and at the time of sacrifice (fasting body weights). Histological examinations of various organs (brain, kidney, liver, small intestine and stomach) were carried out after 28 $\mathrm{d}$ using haematoxylin and eosin as staining agents. The organs were preserved in $10 \%$ formalin solution.

\section{Preparation of granules}

Granules were prepared by wet granulation technique using varying concentrations of PSY, TPSY and PVPK30 for comparative study. CIP was mixed with lactose and granulated using PSY, TPSY and PVP $\mathrm{K} 30(10 \% \mathrm{w} / \mathrm{v}$ solution in IPA) as granulating agents separately. The wet mass was passed through sieve no.12 and the granules were dried at $45{ }^{\circ} \mathrm{C}$ for $30 \mathrm{~min}$. The dried granules were further passed through mesh no.16 and then lubricated with the mixture of talc and magnesium stearate. The granules were evaluated and further compressed into tablets using $10.5 \mathrm{~mm}$ flat punch in rotary tablet press (Mini 2 Remake).

\section{Experimental design}

A simplex centroid design containing 7 experimental runs to evaluate variable drug to thiomer concentration was employed to determine their effect on three responses i.e. mucoadhesive strength, retention time and percent drug release and their interaction therein. The simplex centroid design for a 3-component system (AA, BB and CC) is represented by an equilateral triangle in a 2 -dimensional space shown in fig. 1 . The amounts of thiolated psyllium ( $\mathrm{A}=\mathrm{TPSY}$ ), psyllium ( $\mathrm{B}=\mathrm{PSY}$ ) and carbopol $(\mathrm{C}=$ carbopol) were selected as independent variables (table 1) [25].

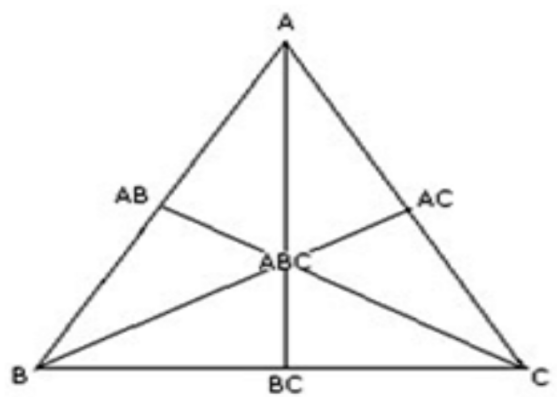

Fig. 1: Equilateral triangle representing simplex centroid design for 3 components $(A, B, C)$.

Table 1: Composition of formulation of ciprofloxacin $\mathrm{HCl}$ tablets prepared according to simplex mixture design with translation of coded levels in actual units (F1-F7)

\begin{tabular}{|c|c|c|c|c|c|c|c|}
\hline \multirow[t]{2}{*}{ Ingredients } & \multicolumn{7}{|c|}{ Formulations } \\
\hline & F1 & F2 & F3 & F4 & F5 & F6 & F7 \\
\hline Ciprofloxacin $\mathrm{HCl}$ & 125 & 125 & 125 & 125 & 125 & 125 & 125 \\
\hline TPSY (A) & $70(1)$ & $40(0)$ & $40(0)$ & $55(0.5)$ & $55(0.5)$ & $40(0)$ & $50(0.33)$ \\
\hline PSY (B) & $40(0)$ & $70(1)$ & $40(0)$ & $55(0.5)$ & $40(0)$ & $55(0.5)$ & $50(0.33)$ \\
\hline Carbopol (C) & $40(0)$ & $40(0)$ & $70(1)$ & $40(0)$ & $55(0.5)$ & $55(0.5)$ & $50(0.33)$ \\
\hline PVP K30 & 35 & 35 & 35 & 35 & 35 & 35 & 35 \\
\hline Talc & 7 & 7 & 7 & 7 & 7 & 7 & 7 \\
\hline Magnesium stearate & 7 & 7 & 7 & 7 & 7 & 7 & 7 \\
\hline Lactose & 26 & 26 & 26 & 26 & 26 & 26 & 26 \\
\hline Total & 350 & 350 & 350 & 350 & 350 & 350 & 350 \\
\hline
\end{tabular}

All values are in $\mathrm{mg},{ }^{*} \mathrm{~A}$ is TPSY, B is PSY and C is Carbopol

\section{Evaluation of tablets}

\section{Physical properties of tablets}

The hardness of the tablets was evaluated using Monsanto Hardness Tester and was also evaluated for weight variation. The tablets were also evaluated for friability using Roche friabilator [20]. Ten tablets were placed in the Roche friabilator, which was then operated for 100 revolutions for $4 \mathrm{~min}$ at $25 \mathrm{rpm}$. After 100 revolutions the tablets were dedusted and reweighed. Percentage friability was calculated by the following formula:

Percentage friability $=[$ (Initial weight of tablets-Final weight of tablets)/Initial weight of tablets] $\times 100$

\section{Mucoadhesive strength and mucoadhesion time}

The mucoadhesive strength of the tablets was evaluated using Texture Analyser (CEB Texture Analyzer, Brookfield Engineering Labs, Inc., Model Texture Pro CT V1.4 Build 17) and mucoadhesion time was evaluated using disintegration apparatus on fresh sheep gastric mucosa by the procedure described previously.

\section{In vitro dissolution studies and release kinetics}

The in vitro dissolution studies were carried out in $900 \mathrm{ml} 0.1 \mathrm{~N} \mathrm{HCl}$ using USP Dissolution Apparatus type I at $37{ }^{\circ} \mathrm{C}$ and $100 \mathrm{rpm}$. Dissolution fluid was withdrawn at regular time intervals during the studies and sink condition was maintained by replacing with an 
equal volume of drug-free dissolution fluid. The samples were suitably diluted with fresh dissolution fluid. The samples were then analysed on a Jasco UV/VIS spectrophotometer (V-530) at $\lambda$ max of $276 \mathrm{~nm}$. Absorbance was measured and percent drug release was determined. The data obtained from in vitro release studies were fitted into various kinetic equations viz., zero order, first order, Higuchi matrix and Korsmeyer-Peppas to know the mechanism of drug release. The equation with high regression coefficient $\left(\mathrm{r}^{2}\right)$ and $\mathrm{n}$ values for formulation will be the best fit of release data. Goodness-of-fit was evaluated using DD Solver 1.0 software.

\section{RESULTS AND DISCUSSION}

\section{Crosslinking of PSY}

Microwave irradiation enhances the reaction rate by providing energy efficient internal heating by direct coupling of microwave energy. In the conventional method, reactants are slowly activated by a conventional external heat source [14]. Microwave method was best suited for the reaction compared to the conventional method as the percent yield was greater in microwave i.e. $74 \%$ as compared to conventional method i.e. $60 \%$. The conventional method required 2 $\mathrm{h}$ for completion of reaction whereas with microwave method the reaction was completed in $20 \mathrm{~min}$.

The covalent attachment of thioglycolic acid to psyllium was achieved by ester bond formation between the hydroxyl group of arabinoxylan moieties of psyllium and carboxyl group of thioglycolic acid as depicted in fig. 2. The finely ground product appeared as a brownish yellow odorless powder, which formed a gel in water.

The average yield amounted to $74 \%$ of the utilized amount of psyllium. The unreacted thioglycolic acid was removed by repeated washings with methanol. TPSY was found to contain $102.35 \mathrm{mmol}$ of thiol groups/g, as determined by the Ellman's method. Dialysis with excess methanol was carried out for removal of unreacted PSY from the freeze-dried sample $[26,27]$.

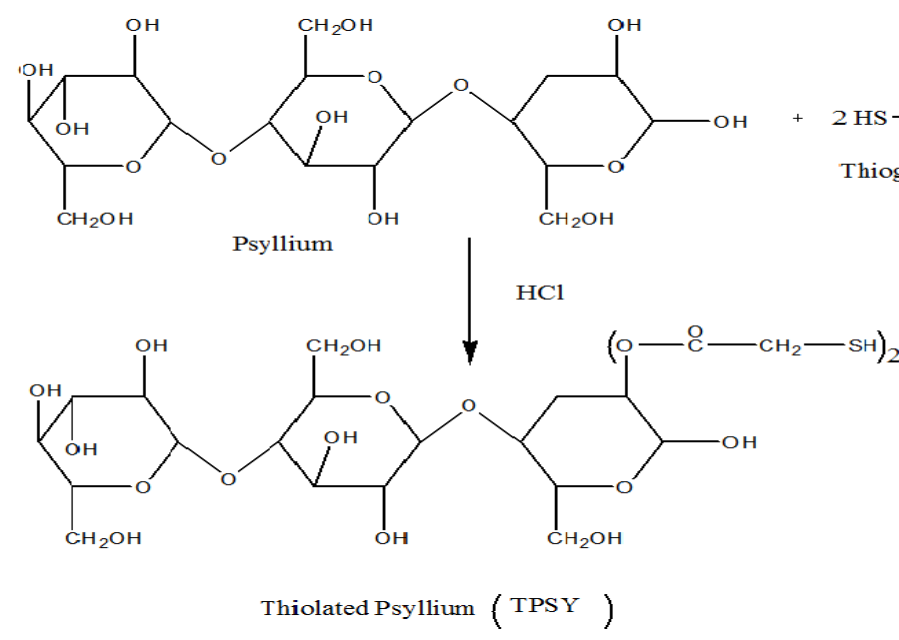

Fig. 2: Thiolation reaction of PSY with thioglycolic acid

\section{Characterization of psyllium seed polysaccharide (PSY) and thiolated psyllium seed polysaccharide (TPSY)}

\section{Swelling profile of PSY and TPSY}

The percent swelling of PSY and TPSY was studied in phosphate buffer $\mathrm{pH} 6.8,0.1 \mathrm{~N} \mathrm{HCl}, 0.5 \mathrm{~N} \mathrm{NaOH}$ and deionised water. For PSY, maximum swelling of $70 \%$ was observed in phosphate buffer $\mathrm{pH} 6.8$ whereas, in deionized water, $55 \%$ swelling was observed. No swelling was observed in $\mathrm{HCl}$. For TPSY, $82 \%$ swelling was observed in deionized water, $75 \%$ in phosphate buffer $\mathrm{pH} 6.8,35 \%$ in $0.5 \mathrm{~N}$ $\mathrm{NaOH}$ and $52 \%$ in $0.1 \mathrm{~N} \mathrm{HCl}$. Swelling is an important criteria for mucoadhesion along with molecular weight and concentration of the polymer and flexibility of polymer chains [28]. Swelling of the polymer was found to increase with respect to time and rate of hydration. The initial contact time affected the percent swelling with higher swelling observed with greater contact time. Interpenetration of polymer chains was enhanced due to increased swelling which facilitated stronger anchoring onto the mucosal surface leading to greater mucoadhesion [29]. Thiol groups on TPSY further strengthen the interaction between the polymer and mucosa thereby enabling maximal mucoadhesion [30].

\section{Solubility profile}

Solubility can be defined as the spontaneous interaction of two or more substances to form a homogenous molecular dispersion. PSY was found to form gel in DMSO, ammonia, $0.5 \mathrm{~N} \mathrm{NaOH}$, water and formamide whereas TPSY was found to be slightly soluble only in formamide and formed a gel in $0.5 \mathrm{~N} \mathrm{NaOH}$, dimethyl sulfoxide, ammonia and water. The formation of gel of TPSY is indicative of its hydrogel nature which can be exploited to design sustained release dosage forms. Hydrogels are three-dimensional, hydrophilic, polymeric networks, with chemical cross-links, capable of imbibing large amounts of water [31]. Hydrogels have been reported as drug delivery systems for modified release dosage forms. Chitosan hydrogels have been used for insulin delivery through oral route and hyaluronic acid hydrogels are reported for drug delivery and tissue engineering [32].

\section{Rheological data}

Rheological investigations of $1 \% \mathrm{w} / \mathrm{v}$ dispersions of PSY and TPSY revealed a continued decrease in viscosity with an increase in shear rate indicating pseudoplastic behavior (fig. 3). Similar results were obtained for tamarind seed polysaccharide [29]. Pseudoplastic systems are shear thinning in nature and are characterised by structural rigidity at rest. Application of shear results in the breakdown of the structure and an apparent fall in viscosity due to the release of entrapped water molecules [33]. TPSY exhibited a sudden breakdown in structure with increase in shear rate. At higher strength, the mucilage has a very rigid structure which can be attributed to the formation of hydrogen bonds between the polysaccharide and water.

The viscosity of TPSY at any shear rate was found to be significantly higher than that of PSY. The viscosity of $1 \%$ dispersion of TPSY at a shear rate of $10 \mathrm{rpm}$ was found to be 1.75 folds higher than that of PSY. The higher viscosity of TPSY at low shear rates will facilitate its mucoadhesive properties as it will contribute to increased residence time of the drug delivery system at the site of use. At the same time, shear thinning properties of TPSY will allow greater flexibility of the polymer chains which is a prerequisite for mucoadhesion. 


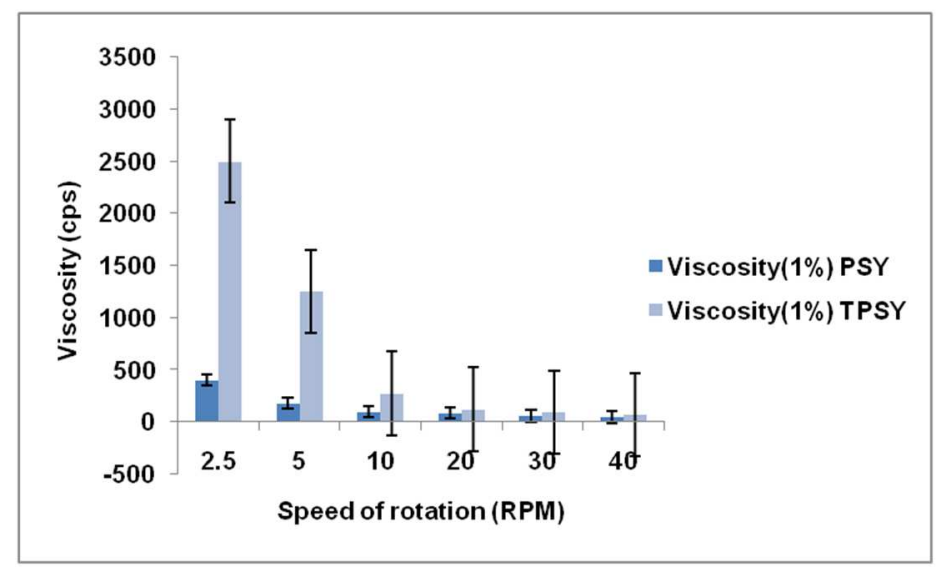

Fig. 3: Evaluation of viscosity of $1 \% \mathrm{w} / \mathrm{v}$ PSY and TPSY gels, mean \pm SD, $n=3$

\section{Mucoadhesive strength}

The mucoadhesive strength of a polymer is dependent on molecular weight of the polymer, contact time with the membrane, the degree of swelling of the polymer and concentration of polymer [29]. The mucoadhesive strength of PSY and TPSY was studied using sheep intestinal mucosa (table 2). TPSY was found to have higher mucoadhesive strength as compared to PSY and carbopol. Carbopol is a hydrogel which swells on contact with water. The extent of swelling depends upon the degree of crosslinking. Hydrogen bonding with mucin is responsible for mucoadhesive properties of hydrogels [35]. Thiolated polymers act by forming covalent disulphide bonds with cysteine-rich subdomains of mucus glycoproteins which build the mucus gel layer [36]. The bond strength of covalent bonds ranges from $50-200 \mathrm{kcal} / \mathrm{mole}$ while a hydrogen bond has the strength of $2-8 \mathrm{kcal} / \mathrm{mole}$ [37]. The higher mucoadhesive strength of TPSY can thus be attributed to the stronger bonds formed between the polymer and mucin. The percent increase in mucoadhesive strength of TPSY was found to be $50.31 \%$ as compared to PSY and $128.30 \%$ as compared to carbopol.

Table 2: Evaluation of mucoadhesive strength and mucoadhesive retention time of PSY and TPSY pellets

\begin{tabular}{lll}
\hline Polymer & Mucoadhesive strength (g) & Mucoadhesive retention time (min) \\
\hline PSY & $16.1 \pm 1.35$ & $62 \pm 0.48$ \\
Carbopol & $10.6 \pm 0.95$ & $70 \pm 0.28$ \\
TPSY & $24.2 \pm 1.17$ & $195 \pm 0.72$ \\
\hline
\end{tabular}

mean \pm SD; $n=3$

\section{Mucoadhesive retention time}

In vitro retention time is an important physical parameter of mucoadhesive polymers. PSY and carbopol were found to have lower residence time compared to the TPSY (table 2). The mucoadhesive retention time of TPSY was found to be $110 \%$ higher than PSY and $50 \%$ higher than carbopol. Increased residence time was observed with increase in the concentration of mucoadhesive polymers in the formulations. This test reflects the mucoadhesive capacity of polymers used in formulations. The results revealed that TPSY showed better bio-adhesion than PSY and carbopol polymer. These results co-related well with results of mucoadhesive force and swelling index.

\section{Spectral analysis}

\section{Fourier transform infrared spectroscopy (FTIR)}

The fig. 4 exhibits the FTIR spectrum of PSY and TPSY in the frequency region from 4000 to $400 \mathrm{~cm}^{-1}$. The spectra of PSY shows a broad absorption band at $3401 \mathrm{~cm}^{-1}$ which can be attributed to$\mathrm{OH}$ stretching of alcohols. The peaks appearing at 1000,740 , and $590 \mathrm{~cm}^{-1}$ may be due to polymer backbone bendings. The IR spectra of TPSY show the absorption band due to $\mathrm{OH}$ stretching at $3425 \mathrm{~cm}^{-1}$, while the-SH stretch appears at $2353 \mathrm{~cm}^{-1}$ which confirms the thiolation. The C-O-C stretch appears at $1000 \mathrm{~cm}^{-1} \mathrm{in}$ TPSY, while the peaks at 770 and $447.50 \mathrm{~cm}^{-1}$ are for polymer backbone bendings.

\section{Powder x-ray diffraction analysis (PXRD)}

XRD patterns are recorded using X-ray diffractometer. Samples were analyzed between $0-80^{\circ}(2 \theta)$. The halo pattern evident in the diffractogram was indicative of the amorphous nature of both PSY and TPSY depicted in fig. 5. During crystallization process, short chain polymers organize themselves into highly ordered crystalline structures more readily than long chain polymers. Polymer morphology is also dependent on the size and shape of the substituent groups [33]. The diffractograms support the DSC findings and we may infer that the thiolated polymer is amorphous in nature.

\section{Differential scanning calorimetry (DSC)}

Fig. 6 compares the DSC thermograms of PSY and TPSY. The thermal curve of PSY shows broad endotherm at $88.79{ }^{\circ} \mathrm{C}$ while the thermogram of TSPY displayed a broad endotherm at $100{ }^{\circ} \mathrm{C}$ as shown in fig. 6. Thus the shift in the endothermic peaks in the thermal curve of TSPY indicates the modification of PSY [38]. The enthalpy values for PSY were found to be- $0.800 \mathrm{~mW}$ and that of TPSY were found to be- $0.780 \mathrm{~mW}$.

The enthalpy of TPSY was higher which indicates that TPSY is more thermally stable as compared to PSY. Enthalpy is a state function that depends only on the prevailing equilibrium state identified by the variables internal energy, pressure, and volume $[39,40]$. Previously reported DSC studies on xyloglucan and thiomer (modified L-cysteine $\mathrm{HCl}$ ) showed a broad endotherm at $54{ }^{\circ} \mathrm{C}$ and $74.59{ }^{\circ} \mathrm{C}$ respectively. The thermogram of thiomer exhibited a sharp endothermic peak $212.57{ }^{\circ} \mathrm{C}$ with heat flow$113.96 \mathrm{~mJ} / \mathrm{g}$ which might be due to combustion of thiomer [41]. Previously reported DSC studies on xyloglucan and thiomer (modified thioglycolic acid) showed broad endotherm at $85.29{ }^{\circ} \mathrm{C}$ while the thermal curve of thiolated TSP showed a broad endotherm at $81.78{ }^{\circ} \mathrm{C}[42]$. 


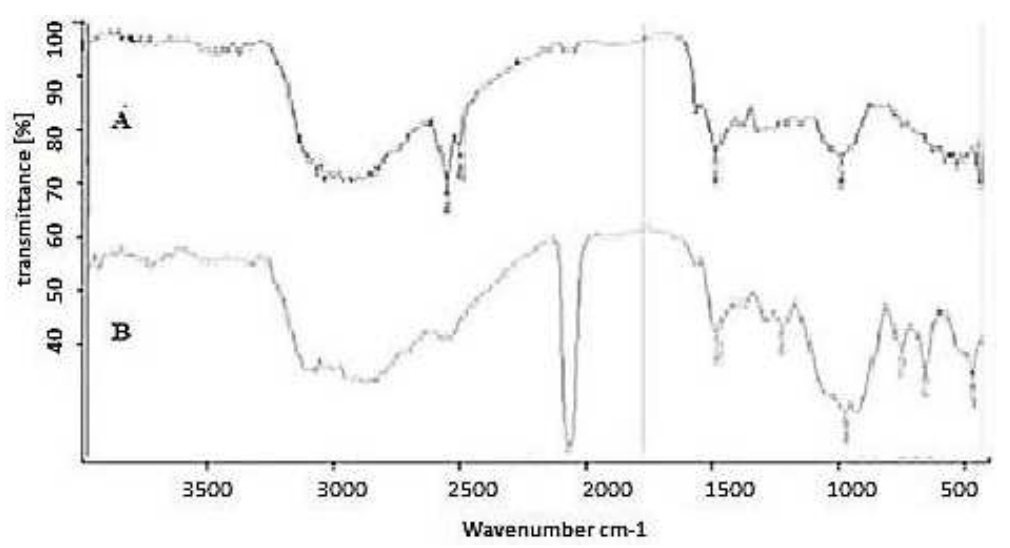

Fig. 4: FTIR spectra of (A) PSY and (B) TPSY

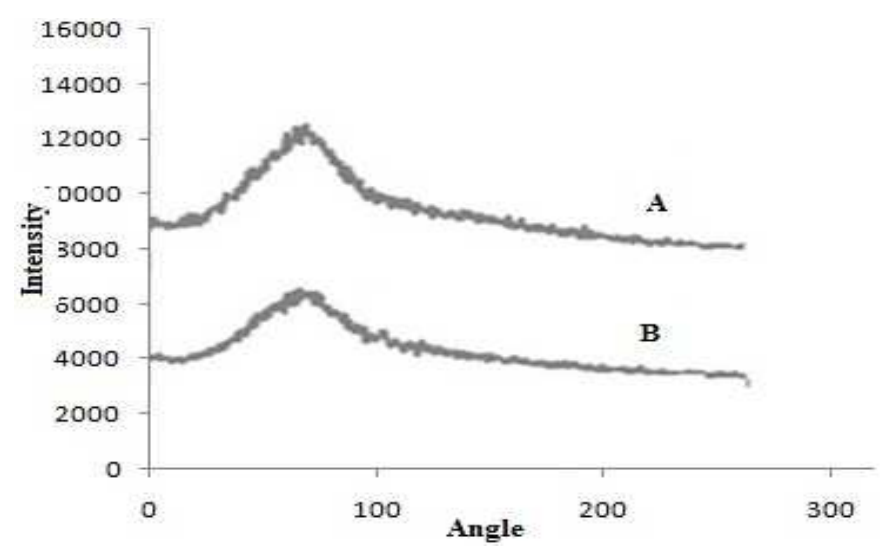

Fig. 5: X-ray diffractograms of PSY and TPSY

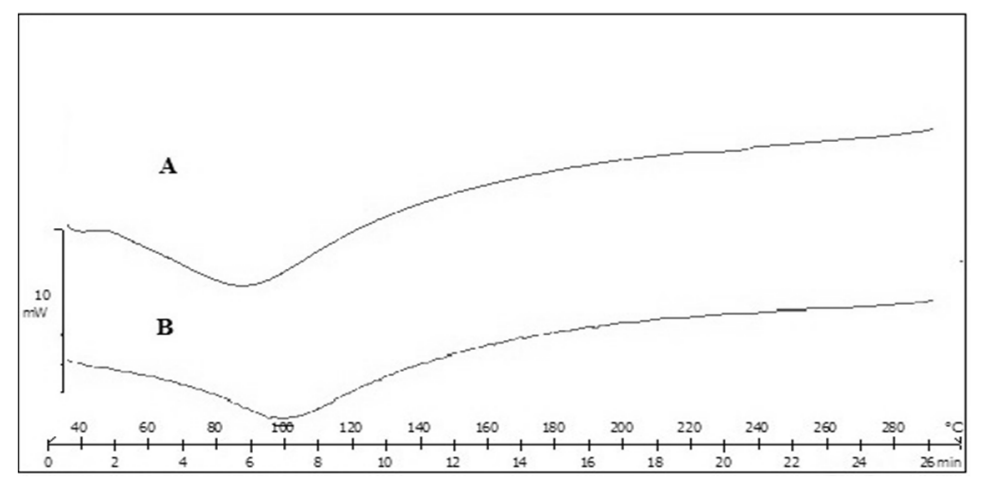

Fig. 6: DSC thermogram of (A) PSY and (B) TPSY

\section{Field emission scanning electron microscopy (FESEM)}

In FESEM, the gun emits the electrons from the much smaller area and the coherency is higher and thus provides better resolution. Fig. 7 shows the shape and surface morphology of PSY and TPSY, examined under an FESEM. The shape of PSY and TPSY particles was found to be polyhedral. A close examination of surface morphology revealed the fibrous appearance of PSY and granular appearance of TPSY.

\section{Acute oral toxicity studies for TPSY}

Acute toxicity refers to the adverse effects that occur on first exposure to a single dose of polymer. Acute oral toxicity studies were conducted according to OECD guidelines. A pilot study was carried out using six male Wistar rats in a group with the starting dose of $300 \mathrm{mg} / \mathrm{kg}$ body weight. Animals were monitored continuously immediately after dosing up to first $4 \mathrm{~h}$ and thereafter for any sign of toxicity or mortality after $24 \mathrm{~h}$ and $14 \mathrm{~d}$. When 300 $\mathrm{mg} / \mathrm{kg}$ dose was found to be non-toxic, a higher dose of $2000 \mathrm{mg} / \mathrm{kg}$ was screened.

At a dose of $2000 \mathrm{mg} / \mathrm{kg}$, the mice showed lethargy during first $4 \mathrm{~h}$ of observation. A slight increase in body weight was observed after $14 \mathrm{~d}$ but no mortality was seen (table 3 ). There were no clinical signs of toxicity like skin rashes, hyperactivity, excessive grooming and kicking of rear legs. Administration of TPSY up to $2000 \mathrm{mg} / \mathrm{kg}$ was well tolerated by the animals. Mean body weight changes and feed consumption were not affected by administration TPSY by oral gavage. Animals in the test groups continued to gain body weights during the study. 


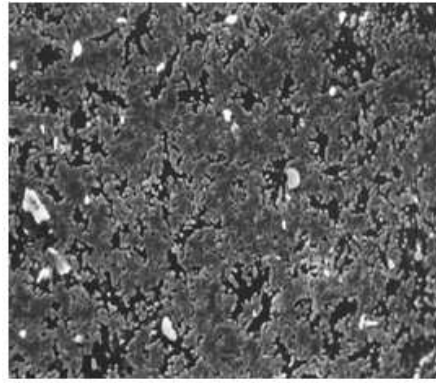

(A) PSY (500X)

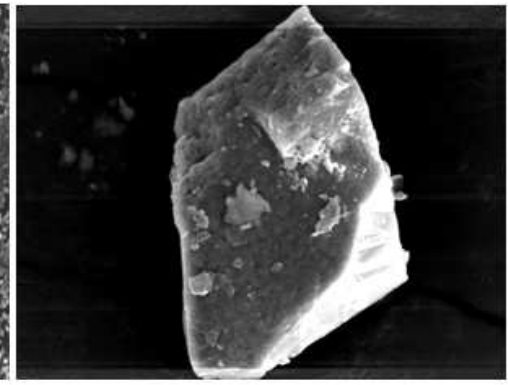

(B) TPSY (15000X)

Fig. 7: FESEM images of (A) PSY (B) TPSY

Table 3: Acute oral toxicity observations at a dose of $2000 \mathrm{mg} / \mathrm{kg}$ body weight of animal

\begin{tabular}{lllll}
\hline S. No. & Parameter & Observation (During 4 h) & Observation (After 24 h) & Observation (After 14 d) \\
\hline 1) & Skin fur & Normal & Normal & Normal \\
2) & Eyes & Normal & Normal & Normal \\
$3)$ & Sleep & Normal & Normal & Normal \\
$4)$ & Lethargy & Normal & Normal \\
$5)$ & Salivation & Normal & Normal & Not Observed \\
$6)$ & Diarrhea & Not Observed & Not Observed & Gain in body weight \\
$7)$ & Body weight & Normal & Noin in body weight & Not Observed \\
$8)$ & Tremors & Not Observed & & \\
\hline
\end{tabular}

$n=6$

\section{Repeat dose oral toxicity studies}

The objective of the repeat dose oral toxicity studies is to identify toxicity, to identify the organs most affected and to determine the doses at which each effect occurs. Male Wistar rats, divided into 4 groups of five rats each, were used for the study. The animals in group 1 served as vehicle control and were administered normal saline daily by oral gavage. The animals in groups 2, 3 and 4 were administered a daily dose of 70, 175 and $350 \mathrm{mg} / \mathrm{kg}$ body weight of TPSY as aqueous suspension by oral gavage for $28 \mathrm{~d}$ respectively. All the animals were observed daily for clinical signs of toxicity and morbidity. Individual animal body weights were recorded at receipt (on day 1) and weekly thereafter and at the time of sacrifice (fasting body weights). The animals were harvested after $28 \mathrm{~d}$ and histological examinations of various organs (brain, kidney, liver, small intestine and stomach) were carried out. The organs were preserved in $10 \%$ formalin solution.

On administration of TPSY, the animals in all groups were found to survive at the end of $28 \mathrm{~d}$ of study. The histological results are shown in table 4. Liver tissue showed minimal degeneration of hepatocytes compared to control at the highest dose of $350 \mathrm{mg}$ which was however reported to be non-toxic.
Mild tubular degeneration was observed in kidneys Stomach tissue displayed moderate changes compared to control, with minimal degeneration of mucosal cellsat highest dose of $350 \mathrm{mg}$. Large intestine showed marked submucosal edema but the mucosal tissue appeared to be normal at the highest dose of $350 \mathrm{mg}$. No abnormality was observed in brain tissues at a low and medium dose. Mild submucosal edema was observed at $350 \mathrm{mg} / \mathrm{kg}$. These results point to the negligible toxicity associated with the thiolated polymer and hence it can be considered to be safe for use as a pharmaceutical excipient.

\section{Evaluation of tablets}

The diameter and thickness of all the batches were found to be 10.51-10.58 $\mathrm{mm}$ and $4.30-4.38 \mathrm{~mm}$ respectively. The weight variation was found to be $0.349-0.354$. The hardness and friability were found to be $5.2-5.8 \mathrm{~kg} / \mathrm{cm}^{2}$ and $0.14-0.21 \%$ respectively. All the parameters were found to be within official limits.

\section{Simplex-centroid design}

A simplex centroid design containing 7 experimental runs to evaluate variable drug to thiomer concentration was employed to determine their effect on three responses i.e. mucoadhesive strength, retention time and percent drug release (table 5).

Table 4: Histological results of repeated dose toxicity studies of TPSY $(n=5)$

\begin{tabular}{|c|c|c|c|c|}
\hline \multirow[t]{2}{*}{ Organs } & \multirow{2}{*}{$\begin{array}{l}\text { Normal saline } \\
\text { Control }\end{array}$} & \multicolumn{3}{|l|}{ TPSY dose strength } \\
\hline & & $70 \mathrm{mg} / \mathrm{kg}$ & $175 \mathrm{mg} / \mathrm{kg}$ & $350 \mathrm{mg} / \mathrm{kg}$ \\
\hline Liver & $\begin{array}{l}\text { Normal architecture of liver, } \\
\text { nothing abnormal detected. }\end{array}$ & $\begin{array}{l}\text { Nothing abnormal } \\
\text { detected. }\end{array}$ & $\begin{array}{l}\text { Minimal degeneration of } \\
\text { hepatocytes. }\end{array}$ & $\begin{array}{l}\text { Minimal degeneration of hepatocyte } \\
\text { and infiltration of inflammatory cells. }\end{array}$ \\
\hline Kidney & $\begin{array}{l}\text { Normal architecture of } \\
\text { kidney, nothing abnormal } \\
\text { detected. }\end{array}$ & $\begin{array}{l}\text { Minimal tubular } \\
\text { degeneration. }\end{array}$ & $\begin{array}{l}\text { Mild tubular degeneration } \\
\text { and congestion of blood } \\
\text { vessels. }\end{array}$ & Mild tubular degeneration. \\
\hline Stomach & $\begin{array}{l}\text { Normal architecture of } \\
\text { Stomach, Nothing abnormal } \\
\text { detected. }\end{array}$ & $\begin{array}{l}\text { Minimal degeneration of } \\
\text { mucosal lining cells. }\end{array}$ & $\begin{array}{l}\text { Mucosal cells were enlarged } \\
\text { and were darkly stained. }\end{array}$ & $\begin{array}{l}\text { Minimal degeneration of mucosal cells, } \\
\text { accumulation of dark staining material } \\
\text { in the gland. }\end{array}$ \\
\hline Brain & $\begin{array}{l}\text { Normal architecture of the } \\
\text { brain, Nothing abnormal } \\
\text { detected. }\end{array}$ & $\begin{array}{l}\text { Nothing abnormal } \\
\text { detected. }\end{array}$ & Nothing abnormal detected. & Minimal neuronal degeneration. \\
\hline $\begin{array}{l}\text { Large } \\
\text { intestine }\end{array}$ & $\begin{array}{l}\text { Papillary projections with } \\
\text { goblet cells. }\end{array}$ & $\begin{array}{l}\text { Mucosal lining no } \\
\text { infiltration of } \\
\text { inflammatory cells. }\end{array}$ & $\begin{array}{l}\text { Minimal infiltration of } \\
\text { inflammatory cells and } \\
\text { congestion. }\end{array}$ & $\begin{array}{l}\text { Marked submucosal edema, mucosal } \\
\text { tissue appears normal. }\end{array}$ \\
\hline
\end{tabular}




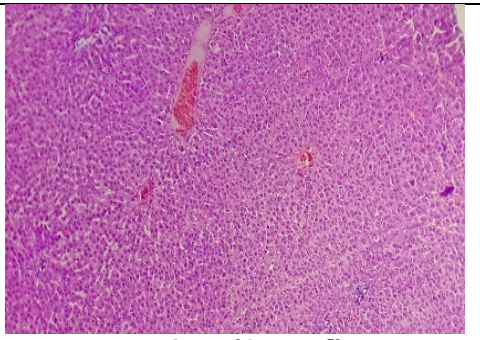

A: Liver (Control)

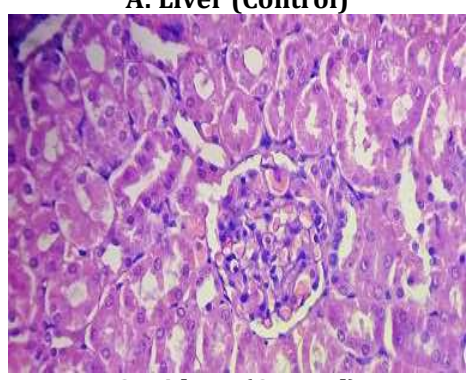

C: Kidney (Control)

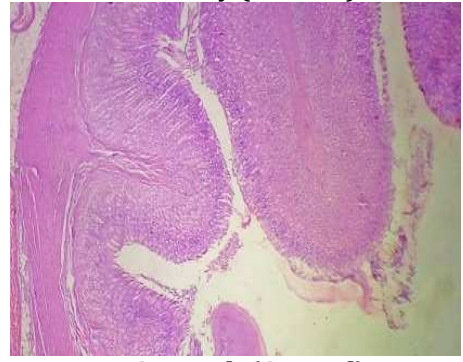

E: Stomach (Control)

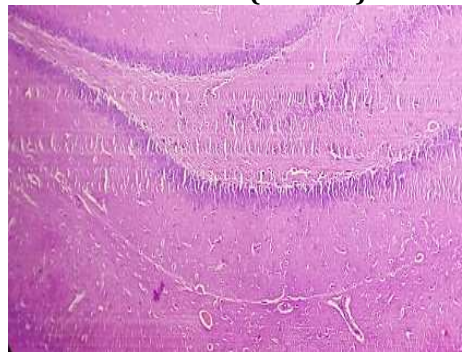

G: Brain (Control)

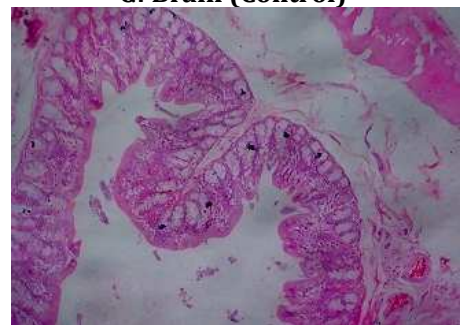

I: Large Intestine (Control)

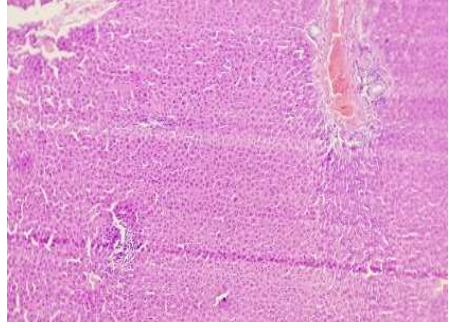

B: Liver (350 mg/kg dose)

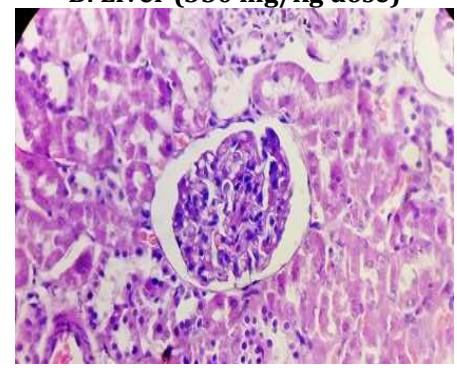

D: Kidney (350 mg/kg dose)

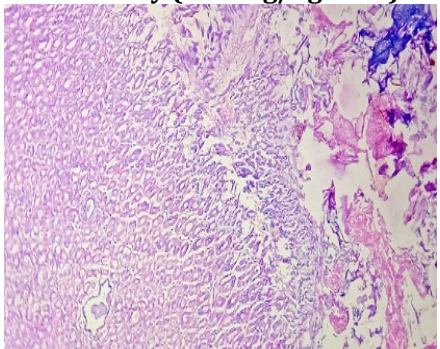

F: Stomach (350 mg/kg dose)

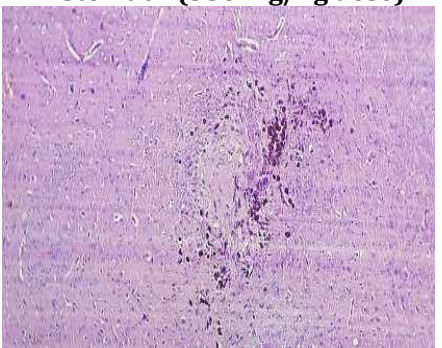

H: Brain (350 mg/kg dose)

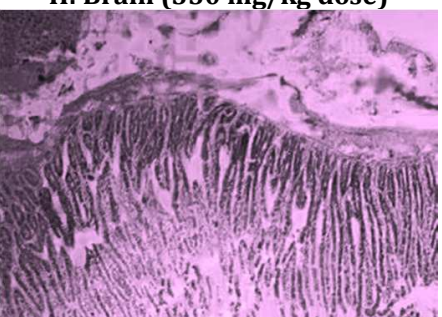

$\mathrm{J:}$ Large Intestine $(350 \mathrm{mg} / \mathrm{kg}$ dose $)$

Fig. 8: Histology of various tissues at highest dose strength of $350 \mathrm{mg} / \mathrm{kg}$ body weight

Table 5: Responses for tablets prepared using simplex centroid design

\begin{tabular}{llll}
\hline Formulation & Response 1 mucoadhesive strength (g) & Response 2 mucoadhesive time (min) & Response 3 \% drug release (\%) \\
\hline F1 & $24.78 \pm 0.21$ & $441 \pm 0.61$ & $90 \pm 0.33$ \\
F2 & $15.24 \pm 0.43$ & $68 \pm 0.46$ & $88 \pm 0,27$ \\
F3 & $14.57 \pm 0.56$ & $62 \pm 0.22$ & $86.5 \pm 0.58$ \\
F4 & $20.96 \pm 0.61$ & $334 \pm 0.45$ & $91.5 \pm 0.68$ \\
F5 & $19.24 \pm 0.24$ & $331 \pm 0.41$ & $91.8 \pm 0.48$ \\
F6 & $13.4 \pm 0.51$ & $122 \pm 0.54$ & $95.82 \pm 0.71$ \\
F7 & $17.6 \pm 0.46$ & $247 \pm 0.82$ & $94.77 \pm 0.821$ \\
\hline
\end{tabular}

${ }^{*}$ mean $\pm \mathrm{SD} ; \mathrm{n}=3$ 


\section{Mucoadhesive strength (g)}

TPSY shows enhanced mucoadhesive strength as compared to PSY and carbopol. This can be attributed to cross linking of PSY with thioglycolic acid (Equation 1). The low coefficients for terms AB, AC and $\mathrm{BC}$ point to the absence of synergistic effect of polymers. The higher coefficient for term A (TPSY concentration) is indicative of its greater mucoadhesive strength than terms B (PSY concentration) and $\mathrm{C}$ (carbopol). This supports our earlier findings regarding the strong covalent bond that thiol functionalization forms with the mucin than the hydrogen bonds which are responsible for the mucoadhesive strength of PSY and carbopol. The Model F-value of 1287.38 implied that the quadratic model is significant which is further substantiated by values of "Prob $>F$ " less than 0.0500 for A, B and C.

Mucoadhesive Strength $=24.79(\mathrm{~A})+15.25(\mathrm{~B})+14.58(\mathrm{C})+3.59(\mathrm{AB})$ 1.95(AC)-6.23(BC) Eq. 1

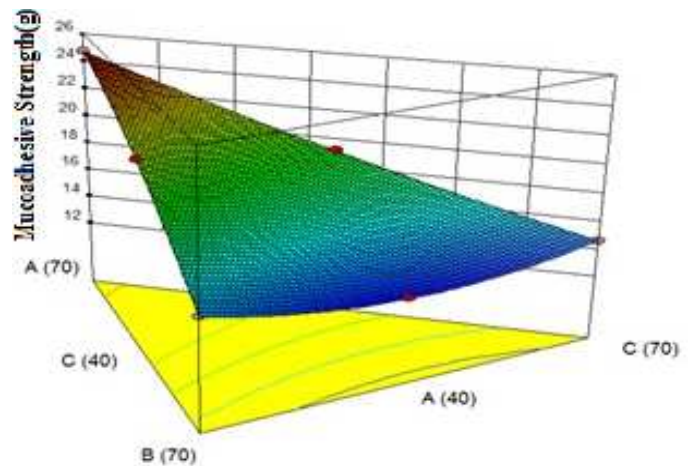

Fig. 9: Response surface graph for mucoadhesive strength where $\mathrm{X} 1=\mathrm{A}=\mathrm{TPSY}, \mathrm{X} 2=\mathrm{B}=\mathrm{PSY}$ and $\mathrm{X} 3=\mathrm{C}=$ Carbopol

\section{Mucoadhesive time (min)}

The mucoadhesive retention time for TPSY was higher as compared to PSY and carbopol which reinforces our findings of mucoadhesive strength. The increased retention time of TPSY can be due to enhanced mucoadhesive strength of TPSY (Eq.2). This may be attributed to the cross linking by thiol moiety. The Model F-value of 269.41 implied the significance of the quadratic model. Values of "Prob $>F$ " less than 0.0500 for A supported the above inference.

Mucoadhesion Time $=$

$7.20(\mathrm{~A})+1.79(\mathrm{~B})+1.19(\mathrm{C})+3.84(\mathrm{AB})+3.84(\mathrm{AC})+3.06(\mathrm{BC}) \mathrm{Eq} .2$

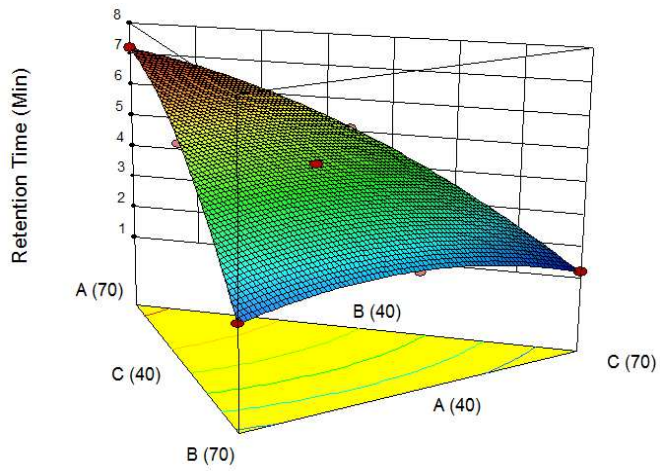

Fig. 10: Response surface graph for mucoadhesion retention time where $\mathrm{X} 1=\mathrm{A}=\mathrm{TPSY}, \mathrm{X} 2=\mathrm{B}=\mathrm{PSY}$ and $\mathrm{X} 3=\mathrm{C}=$ Carbopol

\section{Percent drug release}

TPSY showed greater drug retardation as compared to PSY and carbopol (Eq.3). The Model F-value of 1997.99 implied that the quadratic model was significant. Values of "Prob $>F$ " less than 0.0500 for A, B, C, AB, AC and BC indicated significant quadratic model. The release of the drug from the formulation was found to be comparable with a formulation containing carbopol. It may be concluded that CIP does not interact with polymeric-OH groups due to crosslinking. Formulations F1, F2, F3 and F4 showed $90 \%$, $88 \%$, $86 \%$ and $91 \%$ at the end of 30 min, whereas formulations F5, F6 and F7 showed $90 \%, 95 \%$ and $94 \%$ release in a similar span. It may be due to the fact that as the concentration of polymer increases in formulation its dissolution time decreases thereby it showed lesser drug release from F1 to F5 as shown in fig. 13. The drug release data of the tablet formulations did not fit satisfactorily to zero-order, first-order and Higuchi model equation but fitted well in the Korsmeyer equation $\left(r^{2}=0.995-0.998\right)$. The Korsmeyer-Peppas model is indicative of release of water-soluble drug after penetration of dissolution medium into the polymer networks causing it to swell and dissolve the drug, followed by diffusion along the aqueous pathways to the surface of the device [43].

Drug Release $=$

89.99(A)+87.99(B)+86.49(C)+10.14(AB)+14.34(AC)+34.42(BC) Eq. 3

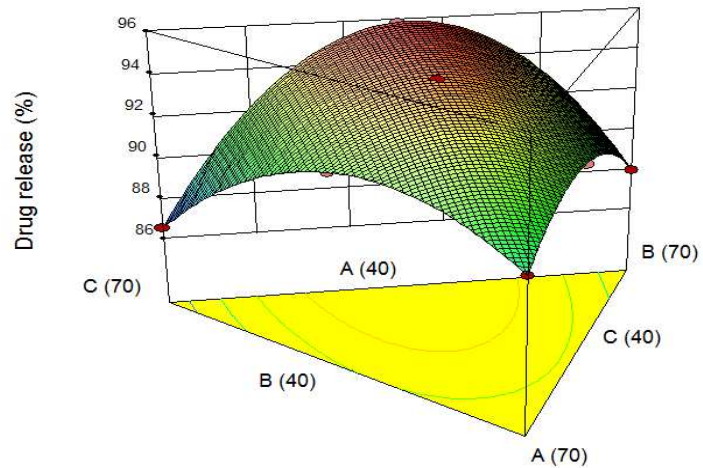

Fig. 11: Response surface graph for drug release where $\mathrm{X} 1=\mathrm{A}=\mathrm{TPSY}, \mathrm{X} 2=\mathrm{B}=\mathrm{PSY}$ and $\mathrm{X} 3=\mathrm{C}=$ carbopol

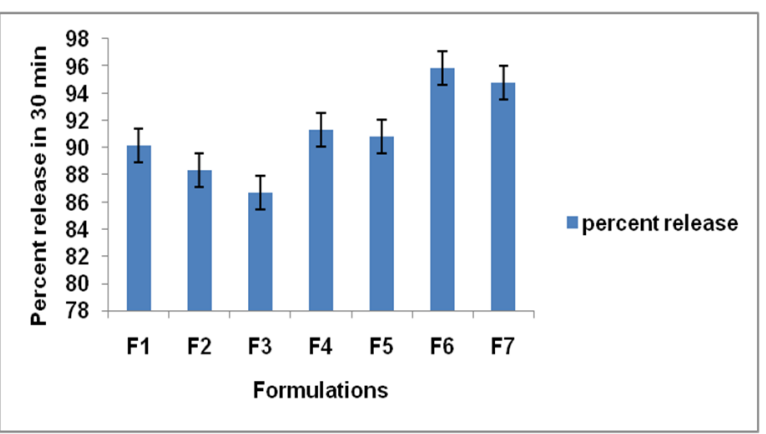

Fig. 12: In vitro drug release from formulations in $0.1 \mathrm{~N} \mathrm{HCl}$ $($ mean $\pm S D$ n=3)

\section{CONCLUSION}

Modification of psyllium was carried out by esterification with thioglycolic acid. Thiolated conjugate was characterized by FT-IR, XRD, DSC and FESEM study. Modified psyllium was employed for formulating mucoadhesive tablets using ciprofloxacin $\mathrm{HCl}$ as the model drug. The percent increase in mucoadhesive strength of TPSY was found to be $50.31 \%$ as compared to PSY and $128.30 \%$ as compared to carbopol. The percent increase in mucoadhesive retention time of TPSY was $110 \%$ as compared to PSY and $50 \%$ as compared to carbopol. The results of acute oral toxicity studies and repeat dose ( $28 \mathrm{~d}$ ) oral toxicity study for thiolated conjugate pointed to the negligible toxicity associated with the thiolated polymer and hence can be considered to be safe for use as a pharmaceutical excipient. We may thus conclude that thiol modification of psyllium resulted in improved its mucoadhesive properties. 


\section{ACKNOWLEDGEMENT}

The authors would like to thank Dr. Ashwini Madgulkar Principal, AISSMS College of Pharmacy, Pune, Maharashtra, India for providing necessary facilities to carry out the research work.

\section{CONTRIBUTION}

The corresponding author, Monica RP Rao has supervised the project. Ms. Snehal Gaikwad has undertaken the project and preparing the draft of the manuscript. Ms Prachi Shevate has helped in drafting and editing the manuscript.

\section{CONFLICT OF INTERESTS}

There is no conflict of interest, financial or otherwise associated with this project.

\section{REFERENCES}

1. Chauhan P, Mehta N. Probiotic assisted colon targeted drug delivery system: research scope. Asian J Pharm Clin Res 2011;4:12-5.

2. Khan M, Ansari V, Kushwaha P, Kumar A, Akhtar J. Mucoadhesive microspheres for controlled delivery of drugs. Asian J Pharm Clin Res 2015;8:1-20.

3. Kumar R, Setia A, Mahadevan N. Grafting modification of the polysaccharide by the use of microwave irradiation-a review. Int J Recent Adv Pharm Res 2012;2:45-53.

4. Aminabhavi T, Chaturvedi K, Ganguly K, Nadagouda M. Polymeric hydrogels for oral insulin delivery. J Controlled Release 2013;165:129-38.

5. Singh B. Psyllium as therapeutic and drug delivery agent. Int J Pharm 2007;334:1-14.

6. Rao MRP, Warrier D, Rao S. Evaluation of phosphorylated psyllium seed polysaccharides a release retardant. Indian J Pharm Sci 2015;77:605-12.

7. Singh B, Sharma V. Design of psyllium-PVA-acrylic acid based novel hydrogels for use in antibiotic drug delivery. Int J Pharm 2010;389:94-106.

8. Singh B, S Kumar. Synthesis and characterization of psyllium-NVP based drug delivery system through radiation crosslinking polymerization. Nuclear Instrum Methods Phys Res 2008; 266:3417-30.

9. Lalge M, Sharma P, Bhandari A, Garud A, Garud N. Mucoadhesive drug delivery system: a review. Crit Rev Pharm Sci 2014:3:17-29.

10. Sarti F, Staaf A. Thiolated hydroxyethylcellulose: synthesis and in vitro evaluation. Eur J Pharm Biopharm 2010;76:421-7.

11. Roldoa M, Hornof M. Mucoadhesive thiolated chitosans as platforms for oral controlled drug delivery: synthesis and in vitro evaluation. Eur J Pharm Biopharm 2004;57:115-21.

12. Shahnaz G, Perera G. Synthesis, characterization, mucoadhesion and biocompatibility of thiolated carboxymethyl dextrancysteine conjugate. J Controlled Release 2010;144:32-8.

13. Kaur H, Yadav S. Synthesis, characterization and evaluation of thiolated tamarind seed polysaccharide as a mucoadhesive polymer. Carb Poly 2012;90:1543-9.

14. Bhosale R, Gangadharappa H, Moin A, Gowda D, Osmani R. A review on grafting modification of polysaccharides by microwave irradiation-distinctive practice for application in drug delivery. Int J Curr Pharm Rev Res 2015;6:8-17.

15. Divate V, Dhongade Desai S. An efficient microwave assisted multicomponent synthesis of some 7-amino-3-(substituted phenyl)-5-(substituted phenyl)-[1,2, 4]triazolo [4,3a] pyrimidine6-carbonitrile derivatives. Int J Curr Pharm Res 2014;6:20-4.

16. Bhatia M, Ahuja M. Thiol modification of psyllium husk mucilage and evaluation of its mucoadhesive applications. Hindawi Publishing Corporation Sci World J 2013;1-7. http://dx.doi.org/10.1155/2013/284182

17. Sena G, Mishra S. Microwave initiated synthesis of polyacrylamide grafted psyllium and its application as a flocculant. Int J Biol Macromol 2012;50:369-75.

18. Berg J, Tymoczko J, Stryer L. Biochemistry $5^{\text {th }}$ ed. WH Freeman. New York; 2002.
19. Khandelwal KR, Practical pharmacognosy, Techniques and experiments. $19^{\text {th }}$ ed. Nirali Prakashan, Pune; 2008. p. 159.

20. Rao MRP, Khambete M, Lunavat H. Study of rheological properties of psyllium polysaccharide and its evaluation as a suspending agent. Int J PharmTech Res 2011;3:1191-7.

21. Patrick S. Martin's physical pharmacy and pharmaceutical sciences. 5th ed. Lippincott Williams and Wilkins, Philadelphia; 2000. p. 587-8.

22. Krishnarajan D. Effect of cellulose and non-cellulose polymers on ciprofloxacin extended-release tablets. J Chem Pharm Res 2012;4:3617-23.

23. Surawase R, Maru A. Formulation and evaluation of metoprolol succinate buccal tablet containing tamarind seed polysaccharides. Int J Pharm Pharm Sci 2011;3:1491.

24. OECD guideline for testing of chemicals-423 Acute Oral Toxicity-Acute Toxic Class Method; 2001.

25. Madgulkar A, Bhalekar M. Optimization of carboxymethylxyloglucan-based tramadol matrix tablets using simplex centroid mixture design. Hindawi Publishing Corporation J of Pharma 2013;1-11. http://dx.doi.org/10.1155/2013/396468

26. Indian Pharmacopoeia. The government of India, Ministry of Health and Family Welfare. Vol. 3. Published by the Indian Pharmacopoeia Commission; 2010. p. 1247.

27. Singh V, Kumara P, Sanghi R. Use of microwave irradiation in the grafting modification of the polysaccharides-a review. Prog Polym Sci 2012;37:340-64.

28. Bhattarai N, Ramay H. PEG-grafted chitosan as an injectable thermosensitive hydrogel for sustained protein release. J Controlled Release 2005;103:609-24.

29. Sravani B, Deveswaran R, Bharath S, Basavaraj B, Madhavan V. Development of sustained release metformin hydrochloride tablets using a natural polysaccharide. Int J Appl Pharm 2012;4:23-9.

30. Tangri P, Khurana S, Madhav S. Mucoadhesive drug delivery: mechanism and methods of evaluation. Int J Pharmacol Biol Sci 2011;3:458.

31. Muraleedhara KK. Mucoadhesive vaginal drug delivery system: a review on advanced status. Int J Pharm Res Anal 2013;3:33-46.

32. Coviello T, Matricardi P, Marianecci C, Alhaique F. Polysaccharide hydrogels for modified release formulations. J Controlled Release 2007;119:5-24.

33. Chaturvedi K, Ganguly K. Polymeric hydrogels for oral insulin delivery. J Controlled Release 2013;165:129-38.

34. Patrick S, Martin's physical pharmacy and pharmaceutical sciences. $5^{\text {th }}$ ed. Lippincott Williams and Wilkins, Philadelphia; 2000. p. 581.

35. Huang $Y$, Leobandung $\mathrm{W}$. Molecular aspects of muco and bioadhesion: tethered structures and site-specific surfaces. J Controlled Release 2000;65:63-71.

36. Qaqish R, Amiji M. Synthesis of a fluorescent chitosan derivative and its application for the study of chitosan-mucin interactions. Carbohydr Polym 1999;38:99-107.

37. Bernkop Schnurch A. Thiomers: a new generation of mucoadhesive polymers. Adv Drug Delivery Rev 2005;58:1569-82.

38. Patrick S. Martin's physical pharmacy and pharmaceutical sciences. $5^{\text {th }}$ ed. Lippincott Williams and Wilkins, Philadelphia; 2000. p. 26,67

39. http://plc.cwru.edu/tutorial/enhanced/files/polymers/orient /orient.htm [Last accessed on 20 Apr 2017]

40. https://en.wikipedia.org/wiki/Enthalpy. [Last accessed on 20 Apr 2017]

41. Madgulkar A, Bhalekar M. Synthesis and characterization of a novel mucoadhesive derivative of xyloglucan. Carbohydr Polym 2016;135:356-62.

42. Kaur H, Yadav S. Synthesis, characterization and evaluation of thiolated tamarind seed polysaccharide as a mucoadhesive polymer. Carbohydr Polym 2012;90:1543-9.

43. Kottke K, Edward M. Tablet dosage forms. In: Banker GS, Rhodes CT. ed. Modern Pharmaceutics. New York: Marcel Dekker, Inc; 2002;1:287-333.

\section{How to cite this article}

Monica RP Rao, Snehal R Gaikwad, Prachi M Shevate. Synthesis and characterization of a novel mucoadhesive derivative of psyllium seed polysaccharide. Int J Pharm Pharm Sci 2017;9(6):166-175. 